\title{
Respostas Hormonais ao Tratamento com GnRH e Estradiol e suas Correlações com Desenvolvimento Testicular e Número de Células Sertoli em Touros Angus x Charolês na Fase de Pré-Puberdade ${ }^{1}$
}

\author{
Arlindo de Alencar Araripe Moura², Bert H. Erickson ${ }^{3}$
}

\begin{abstract}
RESUMO - O objetivo desta pesquisa foi determinar as correlações entre níveis hormonais aos 2 e 6 meses de idade e diâmetro e histologia testicular em tourinhos Angus x Charolês aos 6 meses de idade $(n=15)$. Aos dois meses, duas amostras basais de sangue foram coletadas a intervalos de 1 hora. Após a última coleta, os animais receberam $5 \mu \mathrm{g}$ de GnRH e 1,5 e 3,0 horas depois novas amostras foram coletadas. Aos seis meses, os tourinhos foram tratados com $1 \mathrm{mg}$ de estradiol benzoato (E) e receberam $10 \mu \mathrm{g}$ de GnRH doze horas depois. Após cinco dias, os tourinhos receberam $10 \mu \mathrm{g}$ de $\mathrm{GnRH}$, mas sem pré-tratamento com estradiol. As amostras de sangue foram coletadas 1,5 e 3,0 horas após a injeção de GnRH nas duas ocasiões. Imediatamente antes dos tratamentos com estradiol e GnRH, duas amostras basais foram coletadas. Os animais foram cirurgicamente castrados aos seis meses. Houve correlações entre níveis de FSH estimulados com GnRH aos dois meses e diâmetro testicular e número de células Sertoli e espermatogônias A1 por testículo aos seis meses de idade $(\mathrm{r}=-0,65$ a -0,80). As associações entre FSH aos dois meses e número de seções de túbulos seminíferos sem células germinativas $(\mathrm{r}=0,59)$ e número de túbulos com espermátides circulares $(\mathrm{r}=-0,55)$ também foram significativas. As correlações entre níveis de LH e esteróides e parâmetros testiculares não foram significativas. Aos 6 meses, níveis basais de FSH não alteraram 12 horas após estradiol, mas as concentrações de FSH estimuladas com GnRH foram 2,5 vezes mais elevadas, quando se usou estradiol em relação ao uso somente de GnRH. Modelos de regressão com número de células Sertoli, em função dos níveis de FSH após GnRH, mostraram que, quando se utilizaram GnRH + estradiol, obteve-se maior valor de $\mathrm{R}^{2}(0,43)$ em comparação à injeção somente de $\mathrm{GnRH}(0,30)$. Portanto, concentrações periféricas de FSH são potenciais indicadores do desenvolvimento testicular na fase de pré-puberdade.
\end{abstract}

Palavras-chave: testículo, FSH, estradiol, célula de Sertoli, tourinhos

\section{Hormonal Responses to GnRH and Estradiol Treatments and their Correlation with Testicular Development and Number of Sertoli Cells in Prepubertal Angus x Charolais Bulls}

\begin{abstract}
The objective of this research was to determine the correlation among hormone levels at 2- and 6-month of age and diameter and histology of the testis in Angus x Charolais young bulls at 6 months $(n=15)$. At two months, two basal blood samples were collected at 1-h intervals. After the last collection, the animals received $5 \mu \mathrm{g}$ of $\mathrm{GnRH}$ and 1.5 and $3.0 \mathrm{~h}$ later, new samples were collected. At 6 months, the young bulls were treated with $1 \mathrm{mg}$ of estradiol benzoate (E) and received $10 \mu \mathrm{g}$ GnRH twelve hours later. After five days, the young bulls received $10 \mu \mathrm{g} \mathrm{GnRH}$, but without pre-treatment with estradiol. In both cases, blood samples were collected 1.5 and $3.0 \mathrm{~h}$ after GnRH injection. Immediately before the GnRH and estradiol treatments, two basal samples were collected. The animals were surgically castrated at six months. Concentrations of GnRH-stimulated FSH at two months were related to testis diameter, number of Sertoli cells and A1 spermatogonia per testis ( $\mathrm{r}=.65$ to .80). The associations between FSH at two months and number of seminiferous tubule sections without germ cells $(\mathrm{r}=.59)$ and tubules with round spermatids $(\mathrm{r}=-.55)$ were also significant. The correlations between the basal LH and steroids and testis parameters were not significant. At 6 months, the basal levels of FSH did not alter $12 \mathrm{~h}$ after estradiol, but the FSH concentrations stimulated with GnRH were 2.5-fold higher when estradiol was used than when GnRH was used. Regression models with Sertoli cell numbers in function of FSH after GnRH showed that when GnRH + estradiol was used, a greater $\mathrm{R}^{2}$ (.43) was obtained in comparison to GnRH injection only (.30). Thus, peripheral concentrations of FSH are potential indicators of testicular development at the prepubertal phase.
\end{abstract}

Key Words: testis, FSH, estradiol, Sertoli cell, young bulls

\footnotetext{
${ }_{1}^{1}$ Pesquisa financiada pelo Tenessee Institute of Agriculture e CNPq.

2 Universidade Federal do Ceará - Departamento de Zootecnia, Av. Mister Hull, s/n - Campus do Pici - Caixa Postal, 12.168 - Fortaleza - Ceará - Brasil - 60021-970; Fone: (085) 288 - 9703; Fax: 288 - 9701; E-mail: amoura@ufc.br

${ }^{3}$ Professor Emeritus, Department of Animal Science, The University of Tennessee, USA Knoxville, TN 37901-1071
} 


\section{Introdução}

As células Sertoli têm por função dar suporte estrutural e funcional ao processo de espermatogênese (BARDIN et al., 1994). Nos bovinos, a proliferação destas células inicia-se durante a fase fetal e cessa à idade de 10 semanas pós-parto (SHARPE, 1994). Entre 2 e 3 meses após o nascimento, as células Sertoli apresentam-se imaturas, mas aos 6 meses de idade há evidências de diferenciação, com o desenvolvimento de junções e da barreira sanguíneo-testícular (CURTIS e AMANN, 1981; SINOWATZ e AMSELGRUBER, 1986).

O número de células Sertoli por testículo está associado à produção espermática $\left(\mathrm{R}^{2}=0,68\right)$ e ao peso testicular $\left(\mathrm{R}^{2}=0,56\right)$ em touros adultos (BERNDTSON et al., 1987a, b). Alterações no processo de proliferação das células Sertoli em ratos tratados com radiação (ERICKSON e BLEND, 1976) ou citosina arabinose, substância inibidora da mitose (ORTH et al., 1988), causam reduções no peso testicular. Portanto, fatores que interferem no desenvolvimento de população normal de células Sertoli também afetam de forma significativa a capacidade de produção espermática.

Nos bovinos, os gonócitos proliferam durante a fase fetal (MATSCHKE e ERICKSON, 1969) e neonatal (CURTIS e AMANN, 1981). Por volta dos 2 -3 meses de idade, estes gonócitos começam a se diferenciar em espermatogônias e, aos 6 meses, espermatócitos secundários e espermátidas circulares são formados nos túbulos seminíferos (CURTIS e AMANN, 1981). A população de espermatogônias do tipo A1 está associada ao número de células Sertoli (HOCHEREAU-DE-REVIERS, 1987) e tem influência significativa na produção espermática futura (ORTAVANT et al., 1979), evidenciando que aspectos histológicos dos testículos na fase de prépuberdade podem estar associados à capacidade de produção espermática na fase adulta.

Doses farmacológicas de estradiol aumentam significativamente o intervalo de pulsos de $\mathrm{GnRH}$ (CARATY et al., 1989; D'OCCHIO et al., 1982), diminui temporariamente a capacidade da glândula hipófise de secretar gonadotropinas, mas aumenta, em fase subseqüente, a sensibilidade da hipófise ao efeito do GnRH (CARATY et al., 1989; WILDEUS et al., 1988). O desenvolvimento das células germinativas é controlado por FSH e LH e hormônios secretados pelas células de Leydig e Sertoli (JÉGOU e SHARPE, 1993; SHARPE, 1994), mas não se conhece o grau de associação entre níveis hormonais, sensibilidade da hipófise ao GnRH e estradiol e desenvolvimento testicular. Portanto, este experimento foi conduzido com a finalidade de determinar as correlações existentes entre as concentrações de gonadotropinas e esteróides, basais ou estimulados com GnRH e estradiol e o diâmetro e a histologia testicular durante a pré-puberdade.

\section{Material e Métodos}

\section{Procedimento experimental}

Quinze touros (Angus x Charolês) nascidos no período de 6 de fevereiro a 25 de março de 1993 foram criados a pasto juntamente com as matrizes. A aplicação dos tratamentos foi procedida da seguinte forma:

1. Aos 2 meses: duas amostras basais de soro sanguíneo foram coletadas (veia jugular) a intervalos de 1 hora (6 e 7 h). No momento da última coleta, estes animais receberam por via subcutânea $5 \mu \mathrm{g}$ de GnRH

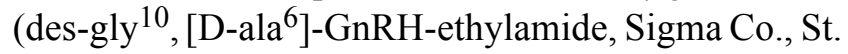
Louis, MO) e amostras de sangue foram coletadas 1,5 e 3,0 horas depois.

2. Aos 6 meses:

Dia 0: duas amostras basais foram coletadas a intervalos de 1 hora (18 e 19 h) e os bezerros receberam $1 \mathrm{mg}$ de estradiol benzoato no momento da última coleta $(19 \mathrm{~h})$.

Dia 1: duas amostras basais coletadas às 6 e $7 \mathrm{~h}$. Os animais receberam $10 \mu \mathrm{g}$ de GnRH no momento da última coleta $(7 \mathrm{~h})$ e novas amostras de sangue foram obtidas 1,5 e 3,0 horas após o GnRH.

Dia 5: os bezerros não receberam estradiol. Duas amostras basais de sangue foram obtidas às $6 \mathrm{e} 7 \mathrm{~h}$ e $10 \mu \mathrm{g}$ de GnRH foram injetado no momento da última coleta. Amostras de soro foram obtidas 1,5 e 3,0 horas depois.

Os animais foram pesados e o diâmetro dos testículos foi medido com o auxílio de paquímetro aos 2 e 6 meses de idade. Os touros foram cirurgicamente castrados aos 6 meses após as coletas de sangue (193 $\pm 2,5$ dias; peso vivo: $215 \pm 10 \mathrm{~kg}$ ).

\section{Análise histológica}

Após a remoção do epidídimo e da túnica vaginalis, dois segmentos de $4 \mathrm{~mm}$ de espessura do parêquima testicular foram fixados em fluido de Bouin (24 horas) e mantidos em etanol a $70 \%$ e posteriormente coradas com hematoxilina e eosina.

Para estimar o estádio de desenvolvimento do epitélio seminífero, 400 secções transversais de túbulos 
foram examinadas em cada touro e classificadas de acordo com as seguintes categorias: túbulos sem células germinativas (ST0), túbulos com espermatogônia A1 (STA), espermatogônia Intermediária ou B (STB), com espermatócitos em paquíteno (STP), espermátidas circulares (STR) e espermátidas alongadas (STE).

A população de células Sertoli e espermatogônias A1 por testículo foi calculada de acordo com o método descrito por ERICKSON e BLEND (1976). O volume testicular (V) foi determinado pela fórmula $\mathrm{V}=\mathrm{PT} \times \mathrm{D}$, em que PT representa peso testicular e $\mathrm{D}$, densidade do parênquima testicular $\left(1,052 \mathrm{~g} / \mathrm{cm}^{3}\right.$, JOHNSON e NEAVES, 1981). O volume ocupado por 10 secções de túbulos (Vst) foi estimado pela fórmula Vst $=\mathrm{Pxh \times}\left(\mathrm{d}^{2} / 4\right)$, em que $\mathrm{h}$ representa a espessura $(5 \mathrm{~mm})$ e d, o diâmetro médio destas secções de túbulos. A porcentagem do volume testicular ocupado por túbulos seminíferos (\% TS) foi determinada conforme o método de CHALKLEY (1943), ou seja, utilizando-se ocular com pontos indicadores, $600 \mathrm{ob}-$ servações foram feitas ao acaso em lâminas e anotado o número de vezes que estes pontos coincidiam com túbulos ou com tecido intersticial. $\mathrm{O}$ número nãocorrigido de células por testículo foi determinado pela fórmula: $\mathrm{N}=(\mathrm{V} x \% \mathrm{TS} \times \mathrm{C}) / \mathrm{Vst}$, em que $\mathrm{C}$ representa o número de células Sertoli e espermatogônias A1 com nucléolo intacto em 10 secções transversais de túbulos. $\mathrm{O}$ valor de $\mathrm{N}$ foi corrigido de acordo com o método de ABERCROMBIE (1946): Número corrigido $=\mathrm{N} \mathrm{x}(5$ $\mu \mathrm{m} /(5 \mu \mathrm{m}+$ diâmetro médio do nucléolo em $\mu \mathrm{m})$. Neste caso, $5 \mu \mathrm{m}$ é a espessura da secção de corte das amostras de tecido. Visto que os animais estavam na fase de pré-puberdade e não apresentavam todos os 12 estádios do ciclo da espermatogênese (BERNDTSON e DESJARDINS, 1974), foram selecionadas somente secções de túbulos em estádio de desenvolvimento mais avançado.

\section{Radioimunoensaios}

Amostras de sangue foram acondicionadas em gelo e, no laboratório, deixadas à temperatura ambiente por 2 horas e centrifugadas a 1764 g, durante 25 minutos. $\mathrm{O}$ soro foi armazenado a $-20^{\circ} \mathrm{C}$. Todas as amostras foram quantificadas no mesmo ensaio para evitar variações entre análises.

As concentrações de FSH foram determinadas em amostras de $200 \mu \mathrm{l}$ de soro por meio de radioimunoensaio (BOLT e ROLLINS, 1983). O primeiro anticorpo (USDA-5-0122) e o FSH purificado para reação com iodo radioativo e curva de referência (USDA-bFSH-I-2) foram cedidos pelo Dr. D. J. Bolt (USDA, Beltsville, MD). O nível de detecção deste ensaio foi de $0,25 \mathrm{ng} / \mathrm{mL}$ e o coeficiente de variação intra-ensaio, $8 \%$. As concentrações de LH foram estimadas em $100 \mu 1$ de soro, conforme o método desenvolvido por NISWENDER et al. (1969) e posteriormente modificado por BOLT (1981). O primeiro anticorpo (LH antiovino no. 15) foi fornecido pelo Dr. G. Niswender (CSU, Fort Collins, CO) e o hormônio purificado para reação com iodo radioativo e curva de referência, pelo Dr. L. E. Reichert (Rochester Medical School, Albany, NY). O nível de detecção foi de 31,3 $\mathrm{pg} / \mathrm{mL}$ e o coeficiente de variação inra-ensaio, $9 \%$.

No caso dos esteróides, as amostras de soro foram primeiramente dissolvidas e extraídas em 1,5 $\mathrm{mL}$ de benzeno. As concentrações de testosterona e androstenediona $\left(\Delta_{4} \mathrm{~A}\right)$ foram estimadas de acordo com o método descrito por COX et al. (1987). O anticorpo para $\Delta_{4} \mathrm{~A}(\mathrm{X}-322 \mathrm{Rao})$ foi adquirido do Dr. P. N. Rao (Southwest Foundation for Biomedical Research, San Antônio, TX) e o anticorpo para testosterona, Dr. G. Niswender. Os níveis de detecção foram 10 e $2,5 \mathrm{pg} / \mathrm{mL}$ para os ensaios de testosterona e $\Delta_{4} \mathrm{~A}$, respectivamente. Os coeficientes de variação intra-ensaio foram 10 e $8 \%$, respectivamente. As concentrações de estradiol foram quantificadas de acordo com o método desenvolvido por COX et al. (1987) e posteriormente modificado para a espécie bovina por intermédio do aumento da diluição do anticorpo de 1:800.000 para 1:1.500.000 e da diminuição da quantidade de soro extraído e utilizado no ensaio (BRITT, comunicado pessoal). O anticorpo foi cedido por Dr. N. Manson (Lilly Research Laboratories, Indianapolis, IN). O nível de detecção do ensaio foi de $0,15 \mathrm{pg} / \mathrm{mL}$ e o coeficiente de variação intra-ensaio, $8 \%$.

Os radioimunoensaios foram validados adicionando quantidades de hormônios a amostras de soro previamente caracterizadas e estimando as concentrações nestas amostras. Os hormônios foram adicionados em concentrações e volumes utilizados nas curvas de referência. Com FSH, 60, 120 e 480 pg foram adicionados a $200 \mu \mathrm{L}$ de soro e, por intermédio do radioimunoensaio, foram detectados $98 \pm 2,99 \pm 3 \mathrm{e}$ $95 \pm 5 \%$ destas quantidades, respectivamente. Foram também adicionados 62, 124 e 488 pg de LH a $100 \mu 1$ de soro e, em todos os casos, $98 \pm 2 \%$ destas concentrações foram detectadas pelo ensaio, em média. No caso dos esteróides, foram adicionados a amostras de $150 \mathrm{~mL}$ de soro e extraídos com 1,5 mL de benzeno 
em uma unidade multitubo Vortex. Dos 5, 20 e 80 pg de $\Delta_{4} \mathrm{~A}$ adicionados, $93 \pm 4,97 \pm 5$ e $95 \pm 4 \%$ destas quantidades foram detectadas pelo ensaio. No caso da testosterona, as mesmas quantidades foram adicionadas a amostras de soro e porcentagens semelhantes foram detectadas pelos ensaios. Com estradiol, 0,$60 ; 3,0$; e $6,0 \mathrm{pg}$ foram adicionados e $99 \pm 3,92 \pm 3$ e $94 \pm 3 \%$ destas quantidades foram detectados no radioimunoensaio. Os valores utilizados nas análises não foram corrigidos, devido a perdas nos ensaios.

\section{Análise estatística}

Os efeitos de GnRH e estradiol benzoato sobre as concentrações hormonais foram avaliados utilizandose a análise de variância (Proc GLM, SAS, 1990). Para cada idade, peso vivo foi usado como covariância, quando significativo $(\mathrm{p}<0,05)$. As correlações entre diâmetro e histologia testicular e níveis hormonais foram estimadas pelo método de correlações parciais de Pearson (Proc CORR, SAS, 1990). Neste caso, peso vivo foi usado com a variável parcial. Modelos lineares de regressão também foram analisados através do SAS (Proc REG).

\section{Resultados e Discussão}

Correlações entre diâmetro e histologia testicular em touros com 6 meses de idade

O diâmetro e peso testicular médio de 15 tourinhos com 6 meses de idade foram de $34 \pm 1 \mathrm{~mm}$ e $48 \pm 6 \mathrm{~g}$, respectivamente. $\mathrm{O}$ número de células Sertoli e espermatogônias A1 por testículo foi de 7,3 $\pm 0,4 \times 10^{9}$ e 4,94 $\pm 0,65 \times 10^{6}$, respectivamente. Com base na análise de 400 secções de túbulos seminíferos por animal, 16,6\% destes não continham células germinativas, $31,5 \%$ tinham espermatócitos, 9,4\% apresentaram espermátidas circulares e em somente 7,5\% dos túbulos foram observadas espermátidas alongadas.

Foram detectadas correlações entre o número de espermatogônias A1 (A1) e o diâmetro testicular (DT; $r=0,61, P<0,05)$ e o número de células Sertoli $(S ; r=0,64, P<0,05)$. A correlação entre $S$ e DT foi de menor magnitude $(r=0,55, \mathrm{P}<0,05)$. Correlações entre histologia e peso testicular também foram significativas $(0,50<\mathrm{r}<0,60 ; \mathrm{P}<0,05)$. Touros com maior número de células Sertoli e A1 apresentaram menor número de túbulos sem células germinativas $(\mathrm{r}=-0,58$, $\mathrm{P}<0,05)$ e maior número de túbulos seminíferos com espermatócitos $(\mathrm{r}=0,59, \mathrm{P}<0,05)$.

A correlação entre as populações de células Sertoli e as espermatogônias A1 encontradas em touros imaturos foi semelhante à determinada por HOCHEREAU-DE RIVIERS et al. (1987) em touros adultos $(r=0,64)$. Portanto, estas correlações evidenciam que as células Sertoli exercem controle sobre o desenvolvimento das células germinativas desde a fase inicial da espermatogênese.

As correlações entre diâmetro testicular e número de células Sertoli encontradas aos 6 meses de idade foram de menor magnitude em relação aos valores encontrados por BERNDTSON et al. $\left(\mathrm{R}^{2}=\right.$ 0,$56 ; 1987 b$ ) em touros com 18 meses e por MOURA e ERICKSON $(r=0,75 ; 1997)$ em touros com 12 meses de idade. A razão desta diferença não é conhecida, mas é possível que as diferenças de idade e, portanto, do número de células germinativas nos túbulos seminíferos dos touros pré-púberes possam ter influenciado estas correlações.

Secreção hormonal após os tratamentos com GnRH aos 2 meses e GnRH e estradiol aos 6 meses de idade

As concentrações de FSH aos 2 meses aumenta$\operatorname{ram}(\mathrm{P}<0,05)$ de $0,821996, \pm 0,06 \mathrm{ng} / \mathrm{mL}$ para $1,59 \pm 0,15$ $\mathrm{ng} / \mathrm{mL}$ e $1,63 \pm 0,18 \mathrm{ng} / \mathrm{mL}, 1,5 \mathrm{~h}(\mathrm{~T} 1,5)$ e $3,0 \mathrm{~h}(\mathrm{~T} 3)$ após o tratamento com $5 \mu \mathrm{g}$ de $\mathrm{GnRH}$, respectivamente (Figura 1A). As concentrações de LH aumen$\operatorname{taram}(\mathrm{P}<0,05)$ de $0,79 \pm 0,06 \mathrm{ng} / \mathrm{mL}$ para $12,69 \pm 1,43$ $\mathrm{ng} / \mathrm{mL}$ no $\mathrm{T} 1,5$, mas a variação no $\mathrm{T} 3$ foi mínima

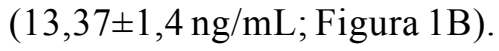

As respostas de testosterona ao $\mathrm{GnRH}$ aos 2 meses apresentaram variações semelhantes às de LH. Níveis basais de testosterona aumentaram $(\mathrm{P}<0,05)$ de $0,25 \pm 0,05 \mathrm{ng} / \mathrm{mL}$ para $0,52 \pm 0,04 \mathrm{ng} / \mathrm{mL}$ no T1,5 e 0,53 $\pm 0,04 \mathrm{ng} / \mathrm{mL}$ no T3 (Figura $2 \mathrm{~A}$ ). O tratamento com $\mathrm{GnRH}$ também causou aumentos nos níveis de $\Delta_{4} \mathrm{~A}$ após o tratamento com GnRH (Figura 2B). As concentrações de estradiol apresentaram variações de $3,3 \pm 0,12 \mathrm{pg} / \mathrm{mL}$ para $3,8 \pm 0,14 \mathrm{pg} / \mathrm{mL}$ no $\mathrm{T} 1,5(\mathrm{P}>0,05)$, mas estes valores aumentaram para $4,5 \pm 0,27 \mathrm{pg} / \mathrm{mL}$ no T3 $(\mathrm{P}<0,05$; Figura $2 \mathrm{C})$.

As respostas de $\mathrm{LH}$ ao tratamento com GnRH foram sempre maiores que as de FSH, comprovando o fato de que a secreção de LH, em comparação com a de FSH, apresenta maior dependência de GnRH (PRICE, 1991). A magnitude das respostas ao GnRH tem sido também demonstrada em outros estudos realizados com touros pré-púberes (MOURA e ERICKSON, 1997) e adultos. MONGKONPUNYA et al. (1975) demonstraram aumentos significativos nos níveis de $\Delta_{4} \mathrm{~A}$ e LH entre 1 e 4 horas após injeções com GnRH em touros aos 2 meses de idade. No entanto, esses autores não encontraram aumen- 
tos significativos nos níveis de testosterona antes dos 4 meses de idade. Resultados apresentados nesta pesquisa e em outros estudos (MOURA e ERICKSON, 1997) mostraram respostas significativas nos níveis de testosterona aos 2 meses, as quais são atribuídas, provavelmente, aos níveis de sensibilidade dos radioimunoensaios.

Aos 6 meses de idade, os níveis de FSH aumentaram para $0,63 \pm 0,06 \mathrm{ng} / \mathrm{mL}$ no $\mathrm{T} 1,5$ e $0,83 \pm 0,10 \mathrm{ng} / \mathrm{mL}$ no T3, quando os animais receberam somente GnRH (Figura 3A). Quando GnRH foi usado com estradiol,
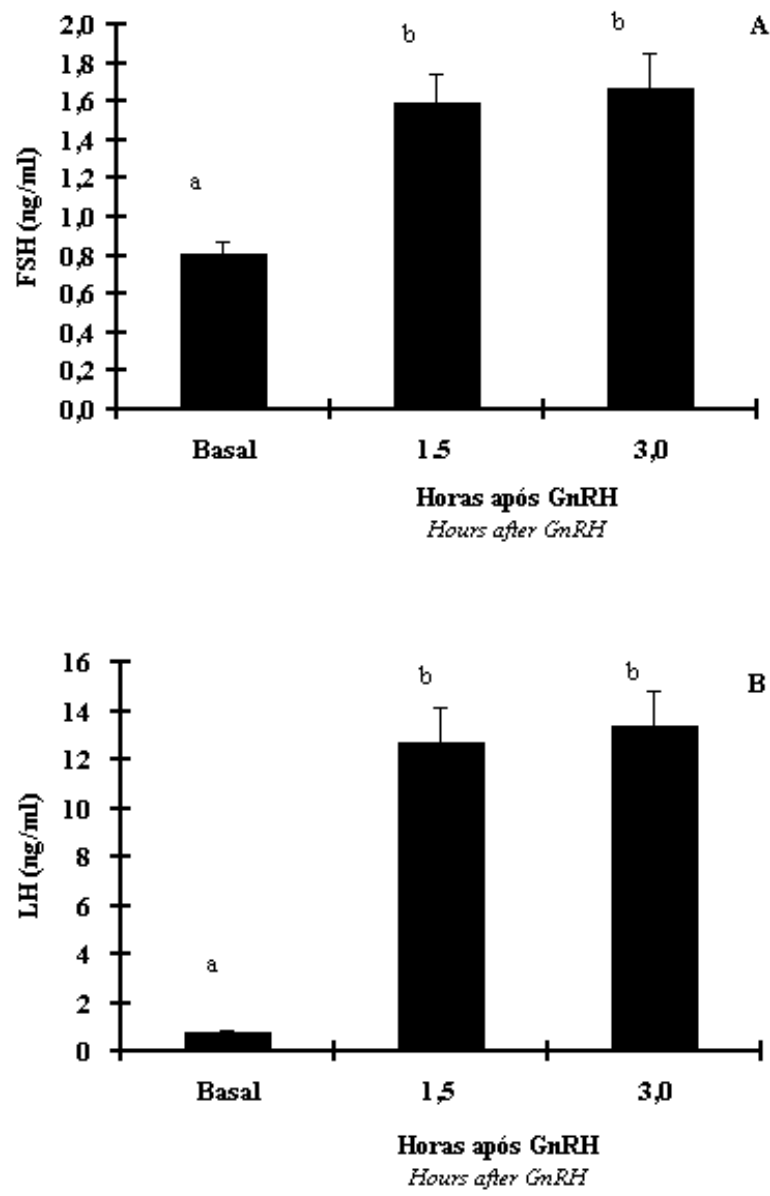

Figura 1 - Concentrações de FSH (A) e LH (B) em touros aos 2 meses de idade $(n=15)$. Duas amostras basais foram coletadas a intervalos de 1 hora. O GnRH foi injetado após a última coleta basal e novas amostras foram obtidas 1,5 e 3,0 horas depois. $a, b$ : diferenças entre os níveis hormonais $(P<0,05)$. Barras verticais representam o erro padrão da média.

Figure 1 - Concentrations of FSH $(A)$ and $L H(B)$ in bulls at 2 months of age $(n=15)$. Two basal samples were coleted at 1 hour intervals. The GnRH was injected at the last basal sample and bulls were bled 1.5 and 3.0 hours afterwards. $a, b$ : diferences among hormone levels $(P<.05)$. Verticals bars represent the standard error of the mean.
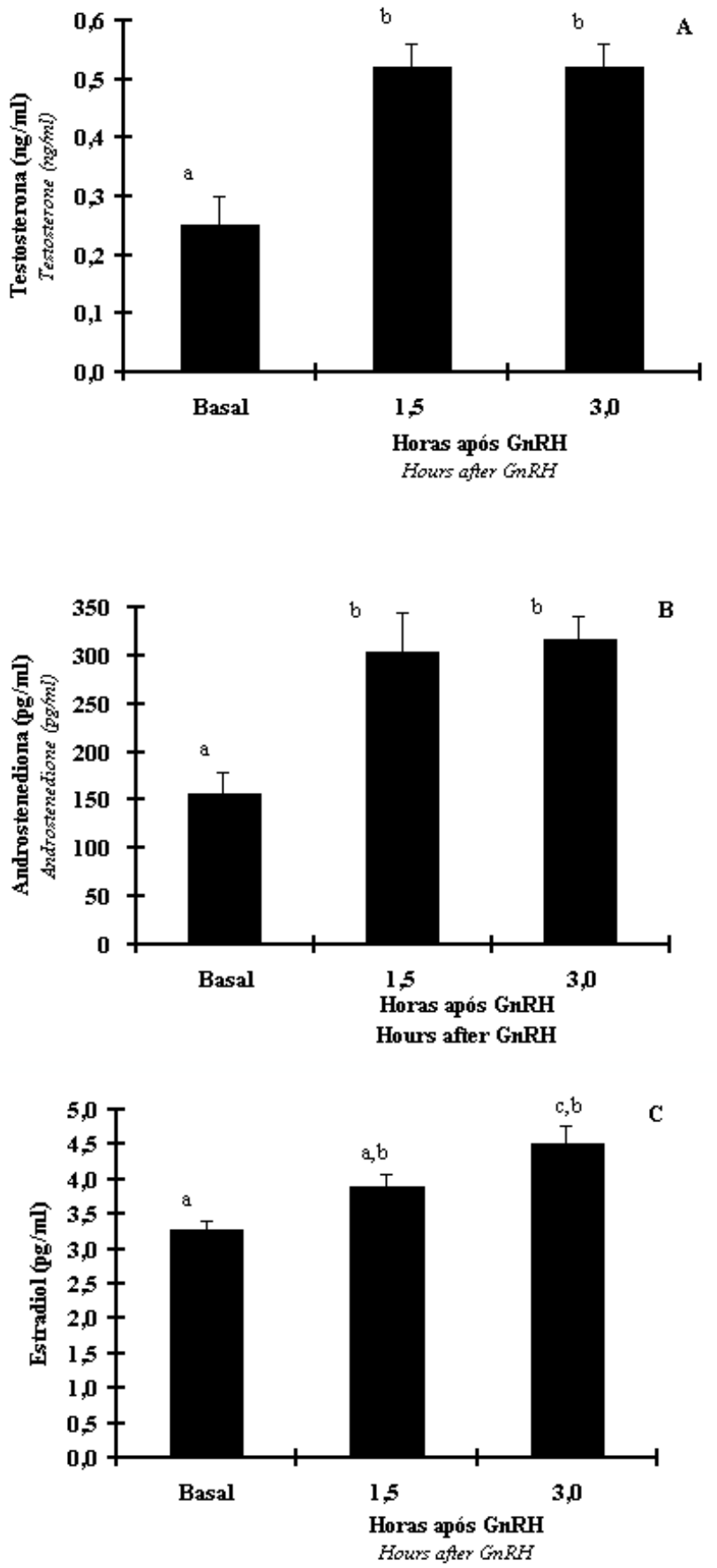

Figura 2 - Concentrações de testosterona (A), androstenediona (B) e estradiol (C) em touros aos 2 meses de idade $(n=15)$. $O \mathrm{GnRH}$ foi injetado após a última coleta basal e novas amostras foram obtidas 1,5 e 3,0 horas depois. $\mathrm{a}, \mathrm{b}$ : diferenças entre os níveis hormonais $(P<0,05)$. Barras verticais representam o erro padrão da média.

Figure 2 - Concentrations of testosterone $(A)$ and androstenedione (B) in bulls at 2 months of age $(n=15)$. The $G n R H$ was injected at the last basal sample and bulls were bled 1.5 and 3.0 hours afterwards. a,b: diferences among hormone levels $(P<.05)$. Verticals bars represent the standard error of the mean. 
as concentrações de FSH aumentaram para 1,2 $\pm 0,21$ $\mathrm{ng} / \mathrm{mL}$ no T1,5 e 2,4 $\pm 0,30 \mathrm{ng} / \mathrm{mL}$ no T3. Os níveis de LH também foram mais elevados após o tratamento com GnRH + E $(33,9 \pm 4,15 \mathrm{ng} / \mathrm{mL}$ no T1,5 e $44 \pm 2,78 \mathrm{ng} /$ $\mathrm{mL}$ no T3) do que quando somente GnRH foi utilizado $(8,33 \pm 0,89 \mathrm{ng} / \mathrm{mL}$ no $\mathrm{T} 1,5$ e $26,9 \pm 1,62 \mathrm{ng} / \mathrm{mL}$ no $\mathrm{T} 3$; Figura 3B). As concentrações de testosterona aumentaram para $1,25 \pm 0,17 \mathrm{ng} / \mathrm{mL}$ no $\mathrm{T} 1,5 \mathrm{e} 2,26 \pm 0,21 \mathrm{ng} / \mathrm{mL}$ no T3 quando GnRH foi usado sozinho, mas estes valores foram mais elevados $(1,77 \pm 0,18 \mathrm{ng} / \mathrm{mL}$ no $\mathrm{T} 1,5$ e $3,2 \pm$ $0,21 \mathrm{ng} / \mathrm{mL}$ no T3) após o tratamento com GnRH e estradiol (Figura 4A). As respostas dos níveis de $\Delta_{4} \mathrm{~A}$ ao GnRH apresentaram resultados semelhantes (Figura 4B).

Avaliações dos efeitos de estradiol sobre as respostas hormonais ao GnRH têm sido realizadas em touros castrados. D'OCCHIO et al. (1982) mostraram que, em touros Angus castrados aos 10 meses, os níveis séricos de LH foram mais elevados quando os animais receberam $2 \mathrm{mg}$ de estradiol por minuto durante 12 horas, seguido de GnRH, em relação ao uso de GnRH sem estradiol. KESNER et al. (1982) também mostraram que a secreção de LH e FSH em resposta a sucessivas doses de GnRH foi amplificada após o tratamento com estradiol durante 20 horas em touros castrados. Da mesma forma, WILDEUS et al. (1988) mostraram que, em touros castrados na pré-puberdade, o tempo necessário para que os níveis séricos de LH estimulados com GnRH retornassem aos níveis basais foi maior quando estradiol foi utilizado 12 horas antes do GnRH. Os resultados do presente trabalho, portanto, enfatizam que em touros não-castrados e com níveis basais de estradiol entre 2 e $6 \mathrm{pg} / \mathrm{mL}$, o tratamento com doses farmacológicas de estradiol também apresenta aumentos nas respostas de gonadotropinas e esteróides ao $\mathrm{GnRH}$.

$\mathrm{O}$ estradiol amplifica as respostas de LH e FSH ao GnRH, provavelmente, por intermédio de ação direta na hipófise anterior. Doses elevadas de estradiol, como as que precedem a onda pré-ovulatória de LH no ciclo estral, causam aumentos no número de receptores de GnRH(MILLER, 1993) e receptores do próprio estradiol, além de estimular a transcrição de genes e a estabilidade de mRNA de hormônios glicoproteicos (KESNER, 1988). Portanto, estes mecanismos devem ter sido induzidos nos touros via estradiol exógeno, evidenciando que a hipófise, ao contrário do hipotálamo, não apresenta dimorfismo sexual (KESNER, 1988).

Os níveis basais de FSH quantificados 12 horas após o tratamento com estradiol $(0,39 \pm 0,02 \mathrm{ng} / \mathrm{mL})$ não apresentaram variações significativas $(\mathrm{P}>0,05)$ quando comparados aos níveis antes do tratamento $(0,49 \pm 0,03 \mathrm{ng} / \mathrm{mL})$. Do mesmo modo, os níveis basais de $\operatorname{LH}(1,83 \pm 0,14 \mathrm{ng} / \mathrm{mL})$ não sofreram alterações 12 horas após o tratamento com estradiol $(1,65 \pm 0,10$ $\mathrm{ng} / \mathrm{mL} ; \mathrm{P}>0,05)$ e, em consequência, os níveis basais de testosterona e $\Delta_{4} \mathrm{~A}$ não foram modificados no mesmo período. Concentrações fisiológicas de estradiol inibem a síntese e secreção de LH e FSH
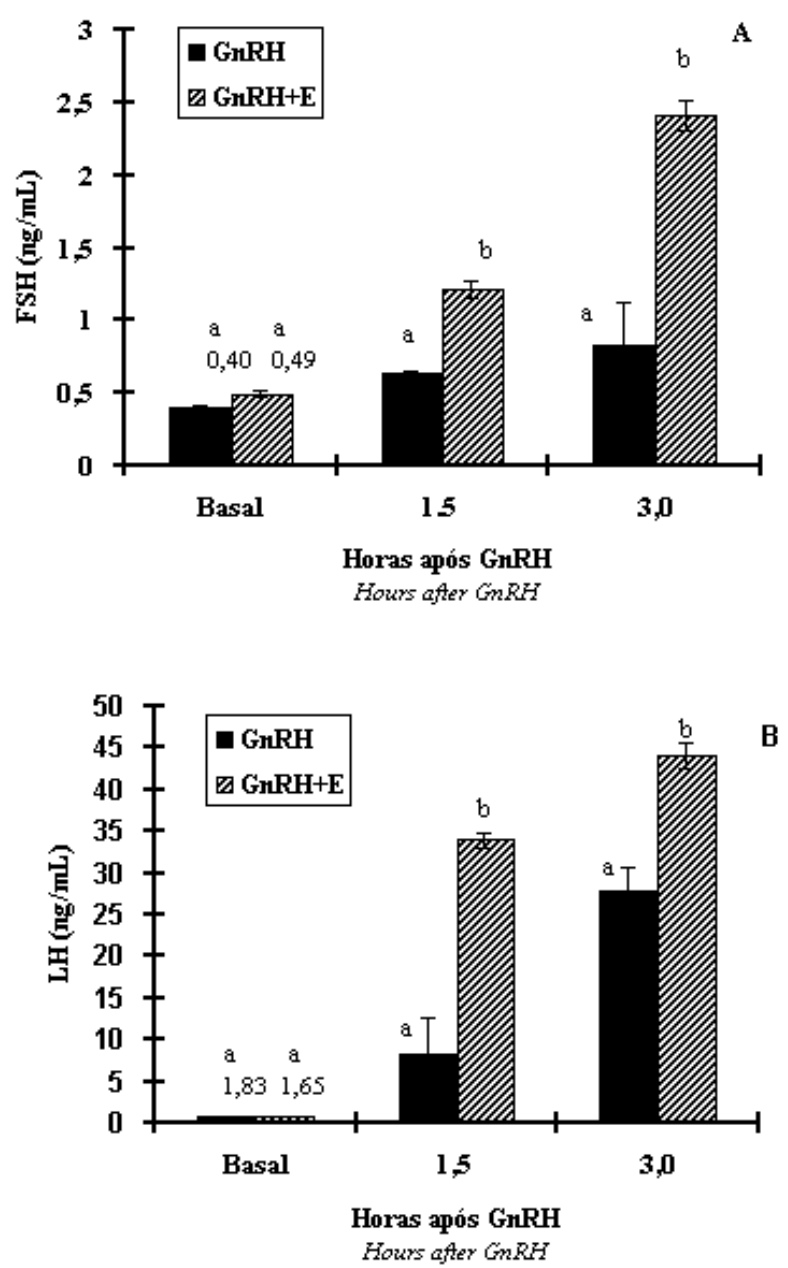

Figura 3 - Concentrações de FSH (A) e LH (B) em touros aos 6 meses de idade $(n=15)$. Os animais foram tratados com $\mathrm{GnRH}$ doze horas após uma injeção de estradiol benzoato $(\mathrm{GnRH}+\mathrm{E})$. Após cinco dias, os touros receberam somente $\mathrm{GnRH}$ $(\mathrm{GnRH})$. O GnRH foi injetado após a última coleta basal e novas amostras foram obtidas 1,5 e 3,0 horas depois. a, b: diferenças entre $\mathrm{GnRH}+\mathrm{E}$ e $\mathrm{GnRH}(\mathrm{P}<0,05)$. Barras verticais representam o erro padrão da média.

Figure 3 - Concentrations of FSH (A) and $L H(B)$ in bulls at 6 months of age $(n=15)$. Animals received $\mathrm{GnRH}$ twelve hours after an injection of estradiol benzoate $(G n R H+E)$. Five days later, bulls received $\mathrm{GnRH}$ only $(\mathrm{GnRH})$. The GnRH was injected at the last basal sample and bulls were bled 1.5 and 3.0 hours afterwards. a,b: diferences between $\mathrm{GnRH}+E$ and $\mathrm{GnRH}(P<.05)$. Verticals bars represent the standard error of the mean. 
Rev. bras. zootec.

Tabela 1 - Correlações entre concentrações de FSH aos 2 meses e parâmetros testiculares avaliados aos 6 meses de idade: diâmetro (DT) e peso testicular (PT), número de células Sertoli (S) e espermatogônias A1 (A1) por testículo e desenvolvimento dos túbulos seminíferos $(\mathrm{n}=15)$

Table 1 - Correlations between concentrations of FSH at 2 months and atributes of the testis at 6 months of age: testis diameter (TD) and weight (TW), number of Sertoli cells (S) and A1 spermatogonia (A1) per testis and degree of seminiferous tubule development $(n=15)$

Parâmetro testicular FSH basal FSH no T1,5 FSH no T3

\begin{tabular}{lccc} 
Testiculartrait & Basal FSH & FSH at T1.5 & FSH at T3 \\
\hline DT $(T D)$ & NS & $-0,70 \mathrm{~b}$ & $-0,75 \mathrm{~b}$ \\
PT $(T W)$ & NS & $-0,61 \mathrm{a}$ & $-0,60 \mathrm{a}$ \\
S & $-0,55 \mathrm{a}$ & NS & $-0,65 \mathrm{a}$ \\
A1 & $-0,77 \mathrm{~b}$ & $-0,80 \mathrm{~b}$ & $-0,75 \mathrm{~b}$ \\
TS0 $(S T 0)$ & $0,66 \mathrm{~b}$ & $0,60 \mathrm{a}$ & $0,59 \mathrm{a}$ \\
TSC $($ STR) & NS & $-0,60 \mathrm{a}$ & $-0,55 \mathrm{a}$
\end{tabular}

FSH basal: média de duas amostras de sangue coletadas a intervalos de 1 hora antes do GnRH.

FSH no T1,5 e T3: concentrações de FSH quantificadas 1,5 e 3,0 horas após $5 \mathrm{mg}$ de $\mathrm{GnRH}$.

TS0: percentagem de túbulos seminíferos sem células germinativas. TSC: percentagem de túbulos seminíferos com espermátidas circulares. $a, b: P<0,05$ e $P<0,01$, respectivamente. NS: não-significativo.

Basal FSH: average of two blood samples taken at 1-h intervals before the $\mathrm{GnRH}$ challenge.

FSH at T1.5 and FSH at T3: concentrations of FSH measured 1.5 and 3.0 h after $5 \mathrm{mg}$ of $\mathrm{GnRH}$.

STO: percentage of seminiferous tubules without germ cells.

STR: percentage of seminiferous tubules with round spermatids.

$a, b: P<.05$ and $P<.01$, respectively. NS: non significant $(P>.05)$.

(MILLER, 1993; NET et al., 1990). Estudos realizados por D'OCCHIO et al. (1982) e WILDEUS et al. (1988) mostraram que os níveis de LH em touros castrados foram reduzidos após o tratamento com estradiol; KESNER et al. (1982) obtiveram os mesmos resultados com FSH. Os tourinhos utilizados neste experimento não apresentaram variações em LH e FSH, provavelmente, porque possível inibição de LH e FSH ocorreu logo após a injeção de estradiol, mas foi superada 12 horas depois pelo aumento na sensibiliddade da hipófise ao GnRH.

As concentrações séricas de $\mathrm{E}_{2}$ em todos os animais apresentaram valores acima de $67 \mathrm{pg} / \mathrm{mL}$ doze horas após o tratamento com estradiol. Estes níveis são mais elevados que os comumente encontrados em animais com 6 meses de idade ( 2 a 6 pg/ $\mathrm{mL}$ ), evidenciando que o estradiol injetado ainda não havia sido totalmente metabolizado. No entanto, 5 dias após o tratamento com $\mathrm{GnRH}+\mathrm{E}$, foram detectadas concentrações basais de 3,08 $\pm 0,24 \mathrm{pg} / \mathrm{mL}, o$ que indica que o estradiol injetado foi metabolizado durante aquele intervalo. Estes níveis basais eleva-
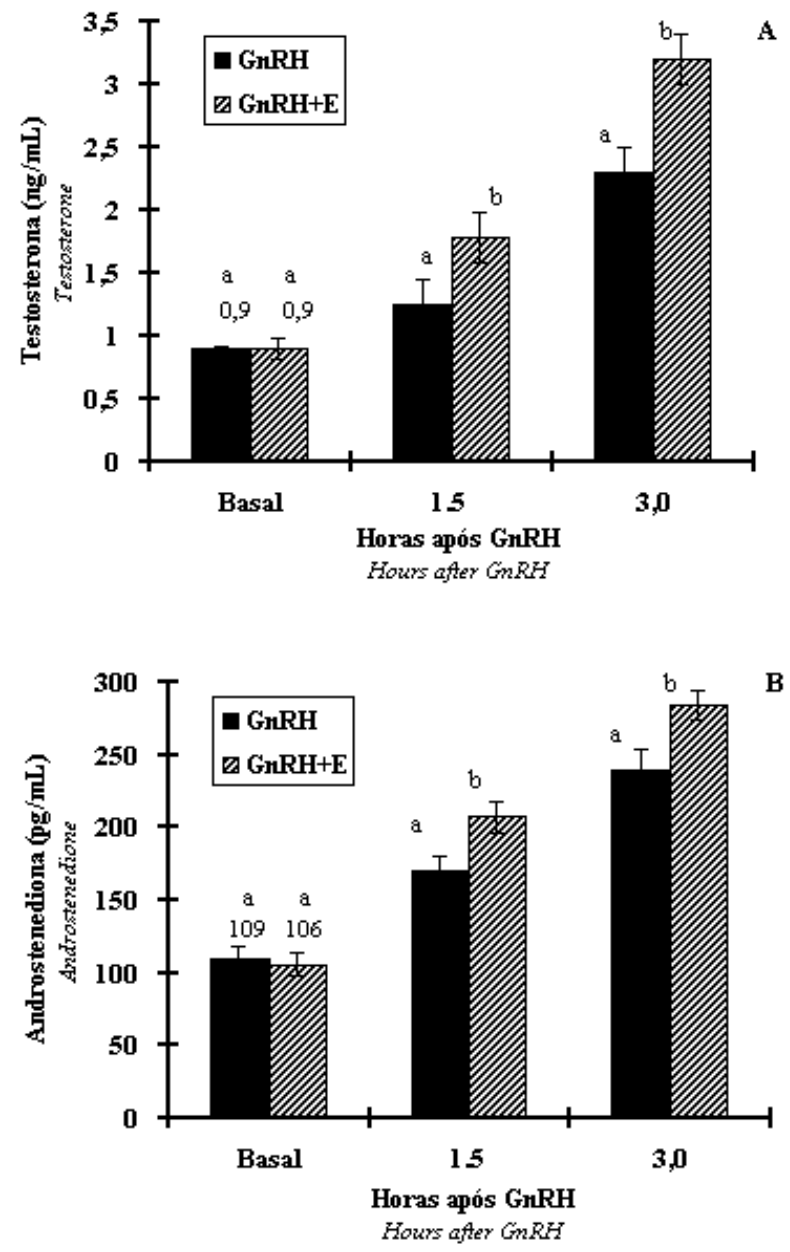

Figura 4 - Concentrações de testosterona (A) e androstenediona (B) em touros aos 6 meses de idade $(n=15)$. Os animais foram tratados com $\mathrm{GnRH}$ doze horas após uma injeção de estradiol benzoato $(\mathrm{GnRH}+\mathrm{E})$. Após cinco dias, os touros receberam somente $\mathrm{GnRH}(\mathrm{GnRH})$. O GnRH foi injetado após a última coleta basal e novas amostras foram obtidas 1,5 e 3,0 horas depois. $a$, b: diferenças entre $\mathrm{GnRH}+\mathrm{E}$ e $\mathrm{GnRH}(\mathrm{P}<0,05)$. Barras verticais representam o erro-padrão da média.

Figure 4- Concentrations of testosterone $(A)$ and androstenedione $(B)$ in bulls at 6 months of age $(n=15)$. Animals received GnRH twelve hours after an injection of estradiol benzoate $(G n R H+E)$. Five days later, bulls received $\mathrm{GnRH}$ only (GnRH). The $\mathrm{GnRH}$ was injected at the last basal sample and bulls were bled 1.5 and 3.0 hours afterwards. a, b: diferences between $\mathrm{GnRH}+\mathrm{E}$ and $\mathrm{GnRH}$ $(P<0,05)$. Verticals bars represent the standard error of the mean. 
ram-se para $5,08 \pm 0,20 \mathrm{pg} / \mathrm{mL}$ e $5,85 \pm 0,32 \mathrm{pg} / \mathrm{mL}$ após o tratamento com $\mathrm{GnRH}(\mathrm{P}<0,05)$.

Correlações entre níveis hormonais aos 2 e 6 meses e diâmetro e histologia testicular aos 6 meses de idade

Foram detectadas correlações entre níveis séricos de FSH após GnRH aos 2 meses e de diâmetro testicular aos 6 meses $(r=-0,75 ; P<0,05 ;$ Tabela 1$)$. Houve também associações inversas entre FSH estimulado com GnRH aos 2 meses e número de células Sertoli $(\mathrm{r}=-0,65, \quad \mathrm{P}<0,05)$ e espermatogônias A1 $(\mathrm{r}=-0,80 ; \mathrm{P}<0,01)$ e entre porcentagem de túbulos seminíferos com espermátidas circulares $(\mathrm{r}=-0,60$, $\mathrm{P}<0,05)$. No entanto, houve associações positivas entre a percentagem de túbulos sem células germinativas aos 6 meses e os níveis de FSH estimulados com GnRH aos 2 meses $(r=0,60 ; \mathrm{P}<0,05)$. As correlações entre parâmetros testiculares e níveis basais de FSH aos 2 meses também apresentaram valores significativos nos casos do número de células Sertoli e espermatogônias A1 e percentagem de túbulos com espermátidas circulares $(r=-0,55$ a $-0,77, \mathrm{P}<0,05$; Tabela 1).

Foram detectadas correlações significativas entre níveis basais de FSH e número de células Sertoli aos 6 meses de idade $(r=-0,54, P<0,05)$. As associações entre FSH estimulado com GnRH e a população de células Sertoli foram significativas nos animais tratados com GnRH $+\mathrm{E}(\mathrm{r}=-0,62$ e - 0,66; $\mathrm{P}<0,02)$ e GnRH $(\mathrm{r}=-0,65$ e $-0,61 ; \mathrm{P}<0,03)$. No entanto, modelos de regressão com $\mathrm{S}$ em função dos valores médios de FSH após GnRH (média de T1,5 e T3) mostraram que, quando GnRH + E foram utiliza$\operatorname{dos}(\mathrm{S}=11,05-1,25 \times \mathrm{FSH})$, obteve-se maior $\mathrm{R}^{2}$ $(0,43 ; p=0,0075)$ do que quando somente $\mathrm{GnRH}$ foi injetado $\left(\mathrm{S}=11,0-2,55 \times \mathrm{FSH} ; \mathrm{R}^{2}=0,30 ; \mathrm{p}=0,036\right)$. Em nenhuma das idades e tratamentos estudados houve correlações significativas envolvendo níveis séricos de $\mathrm{LH}$, testosterona, $\Delta_{4} \mathrm{~A}$ e estradiol.

Estudos têm mostrado a existência de correlações inversas entre FSH e parâmetros testiculares em touros adultos. SWANSON et al. (1971) observaram correlações negativas entre a concentração de FSH na hipófise e a concentração espermática no epidídimo de touros Hereford aos 12 meses de idade $(\mathrm{r}=-0,71)$. MALAK e THIBIER (1985) detectaram relações inversas entre níveis de FSH estimulados com GnRH e qualidade do sêmen $(\mathrm{r}=-0,40$ a $-0,70)$ e SCHANBACHER (1990), correlações negativas entre FSH e diâmetro testicular $(r=-0,70)$ em touros adultos imunizados contra inhibina. Mais recentemente, MOURA e ERICKSON (1997) detectaram correlações inversas entre concentrações de FSH estimadas entre 2 e 12 meses e diâmetro testicular aos 12 meses em touros Angus ( $r=-0,53$ a -0,74). Portanto, os resultados mostram a mesma tendência descrita por outros autores, mas este experimento é o primeiro a mostrar a existência de relações entre FSH e histologia e medidas testiculares desde a fase de pré-puberdade, o que evidencia o restrito controle exercido pelas gônadas sobre a secreção de FSH.

A razão da existência de relações inversas entre FSH e desenvolvimento testicular não são claramente conhecidas, mas é possível que testículos maiores secretam mais esteróides, os quais controlam a secreção de gonadotropinas e a atividade das células Sertoli e de Leydig. No entanto, correlações entre testosterona, estradiol e parâmetros testiculares não foram consideradas significativas neste experimento. Posto que a inhibina regula a secreção de FSH (TILBROOK et al., 1993) e que existe relação inversa entre estes dois hormônios em touros após a idade de 10 semanas (MACDONALD et al., 1990), é possível também que touros com testículos maiores secretem mais inhibina durante a fase de pré-puberdade, o que contribuiria para as relações inversas entre níveis séricos de FSH e parâmetros testiculares. Embora correlações entre inhibina e parâmetros testiculares não tenham sido estimadas em bovinos, a imunização de touros adultos contra inhibina causa aumentos significativos na produção espermática (MARTIN et al., 1991; BAME et al., 1996). Finalmente, o fato de que FSH foi responsável somente por parte das variações em diâmetro testicular indica que outros fatores sistêmicos ou de origem intra-testicular têm importantes funções no processo de desenvolvimento dos túbulos seminíferos.

\section{Conclusões}

Neste experimento, verificou-se que GnRH e estradiol causaram aumentos significativos nos níveis hormonais e amplificaram as correlações entre FSH e parâmetros testiculares. Portanto, as concentrações séricas de FSH estão associadas a importantes aspectos das gônadas durante a pré-puberdade e representam, portanto, indicadores potenciais da capacidade de produção espermática de touros. 


\section{Referências Bibliográficas}

ABERCROMBIE, M. 1946. Estimation of nuclear population from microtome sections. Anat. Rec., 94:239-251.

BARDIN, C.W., CHENG, C.Y., MUSTOW, N.A. et al. 1994. The Sertoli cell. In: E. KNOBIL, J. D. NEIL (Ed.), The Physiology of Reproduction, p. 1291. Raven Press, New York.

BERNDTSON, W.E., IGBOELI, G., PICKETT, B.W. 1987a. Relationship of absolute numbers of Sertoli cells to testicular size and spermatogenesis in younf beef bulls. J. Anim. Sci. 64:241.

BERNDTSON, W.E., IGBOELI, G., PARKER, W.G. 1987b. The numbers of Sertoli cells in mature Holstein bulls and their relationship to quantitative aspects of spermatogenesis. Biol. Reprod., 37:60-72.

BERNDTSON, W.E., DESJARDINS, C. 1974. The cycle of the seminiferous epithelium and spermatogenesis in the bovine testis. Am. J. Anat., 140:167-178.

BAME, J., DALTOM, J.C., DEGELOS, S.D. et al. Immunization against inhibin enhances sperm production in dairy bulls. In: ANNUAL MEETING OF THE SOCIETY FOR THE STUDY OF REPRODUCTION, 29, 1996, London, Ontarion, Canada. 54:138 (abstract).

BOLT, D.J. 1981. Development of homologous radioimmunoassay for ovine follicle stimulating hormone: Studies of estrous, ovariectomy, estradiol and releasing hormone. J. Anim. Sci., 53:730-738.

BOLT, D.J., ROLLINS, R. 1983. Development and application of a radioimmunoassay for bovine follicle stimulating hormone. J. Anim. Sci., 56:146-153.

CARATY, A.A., LOCATElli, A., MARTIN, G.B. 1989. Biphasic response in the secretion of gonadotropin-releasing hormone in ovariectomized ewes injected with estradiol. $J$. Endocrinol., 123:375-386.

CHALKLEY, H. W. 1943. Method for the quantitative morphologic analysis of tissue. Journal of the National Cancer Institute, 4:47-55.

COX, N. M., RAMIREZ, J.L., MATAMOROS, I.A. 1987. Influence of season on estrous and luteinizing hormone responses to estradiol benzoate in ovarioectomized sows. Theriogenology, 27:395-404.

CURTIS, S.K., AMANN, R.P. 1981. Testicular development and establishment of spermatogenesis in Holstein bulls. $J$. Anim. Sci., 53:1645-1654.

D'OCCHIO, M.J., KINDER, J.E., SCHANBACHER, B.D. 1982. Patterns of LH secretion in castrated bulls (steers) during intravenous infusion of androgenic and estrogenic steroids: pituitary response to exogenous luteinizing hormone-releasing hormone. Biol. Reprod., 26:249-257.

ERICKSON, B. H., BLEND, W.J. Response of the Sertoli cell and stem cell to ${ }^{60} \mathrm{Co}$ g-radiation (dose and dose rate) in testes of immature rats. Biol. Reprod., 14:641-652, 1976.

HOCHEREAU-DE RIVIERS, M. T., MONET-KUNTZ, C., COUROT, M. 1987. Spermatogenesis and Sertolicell numbers and function in rams and bulls. J. Reprod. Fert., 34:101-110.

JÉGOU, B., SHARPE, R. 1993. Paracrine mechanisms in testicular control. In: D. de Kretser (Ed.), Molecular Biology of the Male Reproductive System. p. 271. Academic Press, San Diego.

JOHNSON, L., NEAVES, W.B. 1981. Age-related changes in the Leydig cell population, seminiferous tubules, and sperm production in stallions. Biol. Reprod., 24:703-712.

KESNER, J.S. 1988. Site of action for the estradiol-induced luteinizing hormone surge in farm animals and primates. Dom. Anim. Endocr., 5(4):265-281.

KESNER, J.S., RIEBOLD T.W., CONVEY, E..M. 1982. Effect of dosage and frequency of injection of luteinizing hormone releasing hormone on release of luteinizing hormone and follicle stimulating hormone in estradiol-treated steers. $J$. Anim. Sci., 54(5):1023-1029.

MACDONALD, R.D., DEAVER, D.R., SCHANBACHER, B.D.
1990. Prepubertal changes in plasma FSH and inhibin in Holstein bull calves: responses to castration and (or) estradiol. J. Anim. Sci., 69:276-287.

MALAK, G. A., THIBIER, M. 1985. Individual variations in FSH release after a GnRH challenge and relationship with semen output in young bulls. J. Reprod. Fert., 75:345-357.

MARTIN, T. L., WILLIAMS, G. L., LUNSTRA, D. D. et al. 1991. Immunoneutralization of inhibin modifies hormone secretion and sperm production in bulls. Biol. Reprod., 45:73-77.

MATSCHKE, G. H., ERICKSON, B.H. 1969. Development and radioresponse of the prenatal bovine testis. Biol. Reprod., $1: 207-215$.

MILLER, W.L. 1993. Regulation of pituitary gonadotropins by gonadotropin-releasing hormone, estradiol, progesterone, inhibin and activin. In: R. B. L. Gwatkin (Ed.), Genes in Mammalian Reproduction. p. 247. Wiley-Liss, Inc.

MONGKONPUNYA, K., HAFS, H.D., CONVEY, E.M. et al. 1975. Serum luteinizing hormone, testosterone and androstenedione in pubertal and prepubertal bulls after gonadotropin releasing hormone. J. Anim. Sci., 40:682-695.

MOURA, A.A., ERICKSON, B.H. 1997. Age-related changes in peripheral hormonal concentrations and their relationships with testis size and number of Sertoli and germ cells in yearling beef bulls. J. Reprod. Fert. , 111:183-190.

NETT, T. 1990. Regulation of genes controlling gonadotropin secretion. J. Anim. Sci. 68 (Suppl. 2):3.

NISWENDER, G.D., RICHERT, JR. L.E, MIDGLEY, JR., A.R 1969. Radioimmunoassay for bovine and ovine luteinizing hormone. Endocrinology, v. 84, p. 1166-1177.

ORTAVANT, R., COUROT, M., HOCHEREAU-DEREVIERS, M.T. 1977. Spermatogenesis in domestic animals. In: COLE, H. H., CUPPS, P.T. (Ed.), Reproduction in Domestic Animals. p. 203. Academic Press, New York.

ORTH, J.M., GUNSALUS, G.M, LAMPERTI, A.A. 1988. Evidence from Sertoli cell-depleted rats indicates that spermatids numbers in adults depends on Sertoli cells produced during perinatal development. Endocrinology., 122:787-798.

PRICE, C.A. 1991. The control of FSH in the large domestic species. J. Endocr., 131:177-188.

SAS INSTITUTEINC., SAS/STAT®User's Guide, Version 6, Fourth Edition, Volume 2, Cary, NC: SAS Institute Inc., 1989. 846 pp.

SCHANBACHER, B.D. 1990. Pituitary and testicular responses of beef bulls to active immunization against inhibin alpha. $J$. Anim. Sci., 69:252-261.

SHARPE, R.M. 1994. Regulation of spermatogenesis. In: E. Knobil and J. D. Neil (Ed.), The Physiology of Reproduction, p. 1363. Raven Press, New York.

SINOWATZ, F., AMSELGRUBER, W. Postnatal development of bovine Sertoli cells. Anat. Embryol., v. 174, p. 413-422. 1986.

SWANSON, L. V., WETTEMANN, R.P., RAWLINGS, N.C. et al. 1971. Pubertal relationships of some endocrine and reproductive criteria in Hereford bulls. J. Anim. Sci., 33:823-835.

TILBROOK, A. J., DEKETSER, D.M., CLARKE, I.J. 1993. Human recombinant Inhibin A suppress plasma folliclestimulating hormone to intact levels but has no effect on luteining hormone in castrated rams. Biol. Reprod., 49: 779-788.

WILDEUS, S., RANDEL, R.D., HUMPHREY, W.D. 1988. Agerelated changes in the supression of serum luteinizing hormone by estradiol-17b in developing steers. Theriogenology, 29(5):1065-1073.
Recebido em: 27/03/98 Aceito em: 28/08/98 